\title{
Suppression of Soil Dust Emissions from Large-Scale Construction Sites Using Starch and Polyvinyl Alcohol
}

\author{
Jong-Soo Choi, Kwangwoon University, South Korea \\ Dong-Su Kim, Kwangwoon University, South Korea \\ Yu-Lim Choi, Kwangwoon University, South Korea \\ Lakshmi Prasanna Lingamdinne, Kwangwoon University, South Korea \\ Janardhan Reddy Koduru, Kwangwoon University, South Korea \\ iD https://orcid.org/0000-0002-0000-1519 \\ Jae-Kyu Yang, Kwangwoon University, South Korea \\ Yoon-Young Chang, Kwangwoon University, South Korea
}

\begin{abstract}
Soil dust emitted from large-scale construction sites in urban areas impacts air quality and creates a severe health threat to residents. Water spraying is commonly practiced to lower dust emission in construction sites, but its long-term effectiveness is questionable. In this study the utility of starch, polyvinyl alcohol (PVA), and a blend of starch and PVA in various proportions was investigated for the suppression of soil dust emissions at construction sites in Seoul. The efficiency of each dust suppressant was tested with test soil samples in a laboratory-scale wind tunnel box under different concentrations of suppressants and soil textures. Starch and PVA showed superior ability to suppress soil dust emissions compared to moistening bare soil, resulting in $\mathrm{PM}_{10}$ lower than the daily limit values of $30 \mu \mathrm{g} / \mathrm{m}^{3}$. PVA showed higher soil dust suppression capability for all conditions over starch. Test soils sprayed with dust suppressants significantly improved aggregate stability compared to untreated soils.
\end{abstract}

\section{KEYWORDS}

$\mathrm{PM}_{10}$, Polyvinyl Alcohol (PVA), Soil Dust, Starch, Suppressant

\section{INTRODUCTION}

Dust emission is a generic term for dust that is emitted directly into the atmosphere without a certain discharge port (Cohen et al., 2005; Petkova, Jack, Volavka-Close, \& Kinney, 2013). In general, dust in the atmosphere is made up of fine suspended particles that are less than $50 \mu \mathrm{m}$. These are called total suspended particles (TSP). The TSP includes less than $10 \mu \mathrm{m}$ of particulate matter-10 $\left(\mathrm{PM}_{10}\right)$, 
and less than $2.5 \mu \mathrm{m}$ of particulate matter-2.5 $\left(\mathrm{PM}_{2.5}\right)$. According to the 2015 National Institute of Environmental Science statistical data, TSP and $\mathrm{PM}_{10}$ are among the biggest contributors of pollution caused by dust emissions. Most air pollutants are primarily due to dust emissions. Recently, the National Institute of Environmental Science has mandated the forecast and broadcast of fine dust $\mathrm{PM}_{10}$ readings for the metropolitan area (Seoul, Incheon, and Gyeonggi) taking into account atmospheric environmental standards and health impacts. As shown in Table 1, based on the daily average, it is divided into four levels (Park, 2018).

In $2017,97 \%(1,751)$ construction site locations, out of a total of 1,805 locations, reported soil particle scattering in Seoul. Most of the related complaints started at the construction site. Currently, there are intermittent water sprays, water-soluble salt sprays, dust covers, and dust nets being used as countermeasures against the emission of soil dust at these construction sites, but the effects are temporary, and more sustainable measures are required (Seo, 2011).

Starch, a water-soluble natural polymer substance, has a polymer structure consisting of several hundred monomer units. Amylose in the polymer is connected through a straight chain, and amylopectin is connected through a branch chain in the form of a tree branch. Amylose shows a tendency to easily retrograde and precipitate upon cooling. These structural features are biodegradable (Priya et al., 2014) and non-toxic (Lu, Wang, Li, \& Huang, 2018; Wang, Li, Copeland, Niu, \& Wang, 2015).

On the other hand, polyvinyl alcohol (PVA) is a water-soluble surface-active polymer that has excellent film formation, adhesive properties, and it is biodegradable (Priya et al., 2014). PVA, when applied to soil particles, binds the soil surface giving an adhesive effect and also increasing the moisture retention quality of the soil by increasing the capillarity of the dust emissions (Sadhu, Soni, Varmani, \& Garg, 2014). Due to these properties, starch and PVA were selected as dust suppressants in this study. The researchers devised a laboratory-scale, small wind, box tunnel and copied various application conditions and field conditions to investigate the dust suppression effect of starch, PVA, and a mixture of starch and PVA. In addition, the correlation between changes in the formation of soil dust due to the action of dust suppressants and dust suppression efficiency was analysed.

\section{EXPERIMENTAL}

\section{Soil Sample}

Soil samples for the experiment were collected at six construction sites in Seoul, as per the soil pollution process test method outlined by the Ministry of Environment. Soil was collected from a total of five topsoil layers $(0-15 \mathrm{~cm})$, one sample was taken at the centre point, and other samplings, 5-10 m away from the surrounding four directions of the centre point sampling, were the targeted areas in the selected construction sites (Adhikari et al., 2016).

The soil texture of the soil samples was analysed using the sieve analysis method, experimental determination of the drag coefficient, and Stokes' Law equation, which was developed by the United States Department of Agriculture (USDA) (Stokes, 1901). Soil collected from the site was stabilized at room temperature after first removing thick gravel and foreign matter of about 4-5 mm or larger. The soil was dried in the oven, cooled at room temperature, and then a soil suppressant was uniformly sprayed on the soil surface with a compressed sprayer. The processed soil was then used for the experiment after a drying period of $8 \mathrm{~h}$ or more:

Table 1. Daily limit value for $\mathrm{PM}_{10}$

\begin{tabular}{|l|l|l|l|l|}
\hline $\begin{array}{c}\text { Dust Concentration } \\
\left(\boldsymbol{\mu g} / \mathbf{m}^{\mathbf{3}}, \mathbf{d a y}\right)\end{array}$ & Good & Normal & Bad & Very Bad \\
\hline Fine dust, $\mathrm{PM}_{10}$ & $0 \sim 30$ & $31 \sim 80$ & $81 \sim 150$ & $151 \sim$ \\
\hline
\end{tabular}


Stokes'law: $V_{s}=\frac{g\left(\rho_{s}-\rho\right)}{18 \mu} D^{2}$

where ' $V$ ' is a sedimentation rate or velocity of the sphere $(\mathrm{cm} / \mathrm{sec})$, ' $\mu$ ' is a viscosity of a medium $(\mathrm{g} / \mathrm{cm} . \mathrm{sec})$, ' $\rho_{\mathrm{s}}$ ' is particle density $\left(\mathrm{g} / \mathrm{cm}^{3}\right)$, ' $\rho$ ' is a medium density $\left(\mathrm{g} / \mathrm{cm}^{3}\right)$, ' $\mathrm{D}$ ' indicates diameter of the sphere $(\mathrm{cm})$, and ' $\mathrm{g}$ ' is a gravitational force $\left(9.8 \mathrm{~m} / \mathrm{sec}^{2}\right)$.

\section{Wind Tunnel Box Operation}

A wind tunnel box (L: $650 \mathrm{~mm} \times \mathrm{W}: 380 \mathrm{~mm} \times \mathrm{H}: 300 \mathrm{~mm}$ ) was designed to examine the extent of dust emissions due to the application of a dust suppressant. The internal components consisted of a blower, a voltage regulator (slidacs, 0 to $250 \mathrm{~V}$ ) for adjusting the intensity of the blow, an anemometer, a soil dust concentration meter for soil emission, and a test section wherein the sample was placed. The blower was a DLD LD-B118 model that could stably blow at a maximum air volume of $4.3 \mathrm{~m}^{3} /$ min and a maximum wind speed of $24 \mathrm{~m} / \mathrm{s}$. The anemometer was the Flus ET-955 model, the wind speed measurement range was $0.3-45.0 \mathrm{~m} / \mathrm{s}$, and the analysis function was $0.01 \mathrm{~m} / \mathrm{s}$. The fine dust analyser (Temtop, model: M2000) had a measuring range of $\mathrm{PM}_{10}$ or $0 \sim 999 \mu \mathrm{g} / \mathrm{m}^{3}$, and the analysis function was $0.1 \mu \mathrm{g} / \mathrm{m}^{3}$.

In the wind tunnel box test, first, the voltage of the blower was adjusted using slidacs, and the wind speed of the operating condition was set in advance. At this time, the anemometer was fixed between the blower and the soil tray, and then the wind speed value was allowed to stabilize for about one minute. Once stabilized, the soil sample to be tested was placed into a stainless steel laboratory tray (L: $125 \mathrm{~mm} \times \mathrm{W}: 150 \mathrm{~mm} \times \mathrm{H}: 7 \mathrm{~mm}$ ) and placed in the wind tunnel box. The wind tunnel box was sealed so that no air could leave the tunnel. While operating the blower with fixed wind speed to generate dust, the internal dust concentration meter was used to continuously measure the internal dust concentration. At this time, the air of the blower was circulating air within the wind tunnel box.

If the concentration of the dust suppressant is too high, spraying is not achievable due to the viscosity; the surface permeation force of the soil is reduced and the applicability is hindered. If the concentration of the dust suppressant is too low, the formation speed of the dust-binding film on the soil surface is too thin or the formation is incomplete, and the cohesive force of the soil particles is not strong enough. Therefore, the dust concentration of the pre-selected dust suppressant was measured for the emitted concentration of each soil texture.

The dust suppressant solution was produced by adding distilled water to $10 \mathrm{~g}$ of each starch and PVA (Samchun chemical) solids so that the total volume became $1.0 \mathrm{~L}$. To evenly spread the amount of dust suppressant solution a $60 \mathrm{~mL}$ solution was used for $250 \mathrm{~g}$ of the soil sample. The application concentrations of dust suppressants were set to $0.01,0.05,0.1,0.5$, and $1.0 \mathrm{~g} / \mathrm{L}$. The wind speed conditions in Seoul City has an average wind speed of $2.3 \mathrm{~m} / \mathrm{s}$, an average maximum wind speed of $7.8 \mathrm{~m} / \mathrm{s}$, and an average maximum wind speed of $14.2 \mathrm{~m} / \mathrm{s}$. Based on the data, an average maximum wind speed of $14 \mathrm{~m} / \mathrm{s}$ was used for the test. The tray containing the soil sample was set up at an angle of 20 degrees from the bottom and installed in the same manner as the slope of the earth and sand on the construction site. The fine dust measurement carried each at 10-second time intervals during 100 seconds of the wind box operation.

\section{Aggregate Stability}

In order to investigate the long-term effect of the dust suppressant, a dust suppressant was applied at $0.05 \mathrm{~g} / \mathrm{L}$ to soil in an indoor environment with a temperature of $25 \pm 3^{\circ} \mathrm{C}$ and relative humidity of $45 \pm 5 \%$. Enrolment stability tests were conducted at weekly intervals for a total of 12 weeks. In the soil aggregate, a plurality of dispersed soil particles bonded together to form a large lump. Based on the experiments, it was observed that the higher binding effect of the dust suppressant resulted in lower $\mathrm{PM}_{10}$ values. 
In general, the effect of aggregation can be ascertained by determining the value of aggregate stability. Enrolment stability was calculated using the Kijkelkamp wet sieving apparatus, and analysed by substituting into the aggregate stability (\%) equation (Reinhart \& Vermeire, 2016). First, after separating a soil sample having a particle size range of 1 to $2 \mathrm{~mm}, 4 \mathrm{~g}$ of air-dried soil (total particle weight) are placed in a wet sieving apparatus $(0.26 \mathrm{~mm})$. Then, the aggregate dispersed in the water is removed, and the remaining aggregate is dispersed using a dispersant.

In the case of a dispersant to be used, $0.2 \%$ sodium hexametaphosphate is used when the $\mathrm{pH}$ of the soil is more than 7 , and $0.2 \% \mathrm{NaOH}$ is used when the $\mathrm{pH}$ is less than 7 . The soil sample was $\mathrm{pH}$ 7.6, therefore $0.2 \%$ sodium hexametaphosphate was selected as a dispersant. The weight of the soil that remains after being dispersed in water for the first time is known as "the remaining weight," and the weight that remains after being dispersed by the dispersant becomes "the mass of the particles (particles mass)":

Aggregate stability $(\%)=\frac{\text { the remaining weight }(g)-\text { particles mass }(g)}{\text { total particleweight }(g)-\text { particlesmass }(g)} \times 100$

\section{RESULTS AND DISCUSSION}

\section{Sample Soil Texture}

Soil samples that were collected from six points were analysed using a soil texture analysis. As a result, five points were identified as sandy loam and one point was identified as loamy sand (Table 2). Point A was selected for the loamy sand experiment group, and point $F$ was selected for the sandy loam experiment group. The particle size distribution result of point $\mathrm{A}$ and $\mathrm{F}$ samples was developed using a particle distribution analyser (measurable range: $0.375 \mathrm{~mm}$ to $2000 \mathrm{~mm}$ in the Fraunhofer model) was emitted and classified as an air pollutant. The distribution of TSP, PM $_{10}$ particles in the emitted dust showed $17.0 \%$ and $6.5 \%$, respectively in point $\mathrm{A}$, and the particle size distribution results of point $\mathrm{F}$ showed $11.2 \%$ and $3.0 \%$, respectively (Figure 1).

\section{Effect of Dust Suppressant}

First, for sandy loam, Figure 2 shows the effect of $\mathrm{PM}_{10}$ dust on each sample treated with dust suppressant at various concentrations, which is measured using a fine dust analyser every 10 seconds during the 100 secexperimental operation. An excellent emitting suppression effect was shown. The concentration of emitted soil dust corresponding to the "good" range, 0-30 $\mu \mathrm{g} /$ $\mathrm{m}^{3}$ is the average standard of fine dust per day according to the Ministry of the Environment report shown at Table 1 .

\section{Table 2. Texture of collected soil}

\begin{tabular}{|l|l|l|l|l|}
\hline \multicolumn{1}{|c|}{ Location } & \multicolumn{1}{c|}{ Sand (\%) } & \multicolumn{1}{c|}{ Silt (\%) } & \multicolumn{1}{c|}{ Clay (\%) } & \multicolumn{1}{c|}{ Soil Texture } \\
\hline A & 74.2 & 13.2 & 12.6 & Sandy loam \\
\hline B & 66.0 & 18.5 & 15.5 & Sandy loam \\
\hline C & 69.9 & 15.6 & 14.5 & Sandy loam \\
\hline D & 69.1 & 16.8 & 14.1 & Sandy loam \\
\hline E & 79.6 & 10.4 & 10.0 & Sandy loam \\
\hline F & 85.5 & 4.5 & 9.0 & Loamy sand \\
\hline
\end{tabular}


Figure 1. Size distribution results of selected soils: (a) Sandy loam; (b) Loamy sand
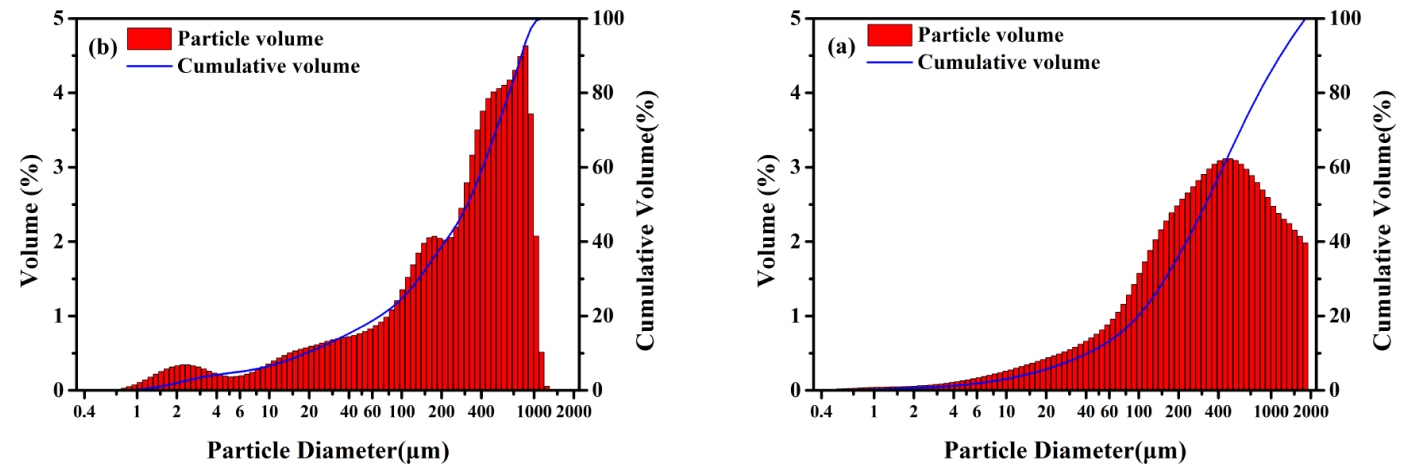

Figure 2. $\mathrm{PM}_{10}$ emissions of sandy loam soil after treated with dust suppressants: (a) Starch; (b) PVA; and (c) Blended starch and PVA
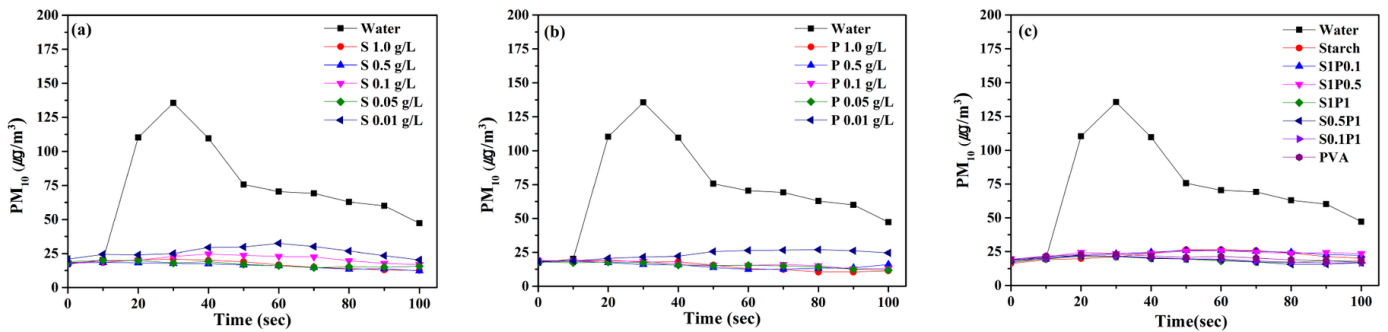

In the case of starch and PVA, the emitting suppression efficiency increased as the applied concentration as a whole increased, however, it did not show a significant difference over the 0.05 $\mathrm{g} / \mathrm{L}$ concentration. When starch and PVA were blended and applied at different ratios based on the optimum concentration value of $0.05 \mathrm{~g} / \mathrm{L}$, which was obtained in the above experiment, the best efficiency was shown at a ratio of 1:1.

Looking at the effect of the $\mathrm{PM}_{10}$ emitting suppression on loamy sand (Figure 3), compared to the blank (water alone), the sample treated with starch showed an excellent emitting suppression effect as the concentration increased. For soil treated with $0.5 \mathrm{~g} / \mathrm{L}$ of starch, the result of dust suppression was within the acceptable range. On the other hand, although it showed an excellent emitting suppression effect compared to the blank under the conditions of all concentrations selected in the experimental conditions in the case of PVA, this was an average standard

Figure 3. $\mathrm{PM}_{10}$ emissions of loamy sand soil after treated with dust suppressants: (a) Starch; (b) PVA; and (c) Blended starch and PVA
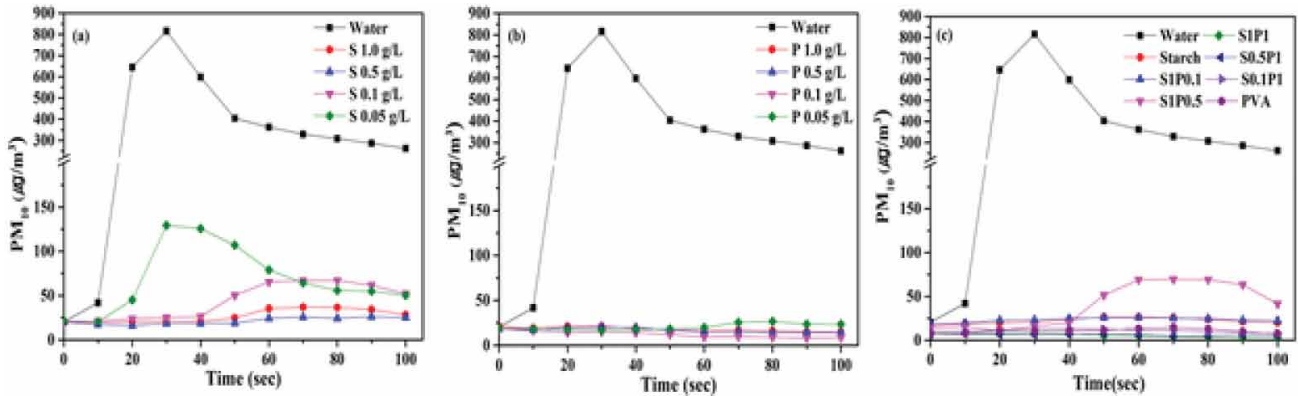
of "good"for fine dust days. The concentration of emitted soil particles corresponding to the range $\left(0-30 \mu \mathrm{g} / \mathrm{m}^{3}\right)$ as was shown in Table 1 . When starch and PVA were blended and applied at different ratios based on the experiment, the optimum concentration of $0.5 \mathrm{~g} / \mathrm{L}$ was obtained and best efficiency was shown at a ratio of 1:1.

Developing these materials was cost-effective (\$5.9 US) when compared to well-known fine dust suppressing agents, such as $\mathrm{MgCl}_{2}$ (\$1,200 US), $\mathrm{CaCl}_{2}$ (\$1,700 US), poly acroylide amide (PAM) ( $\$ 500$ US), and Chlortex (\$16,800 US) for suppression of kilometre area fine particles. Moreover, the present materials were effective for suppression of fine particles. Hence, the developed materials are feasible and economical for industrial application (Choi et al., 2018; Seo, 2011).

\section{Aggregate Stability Using Application of Dust Suppressant Over Time}

Figure 4 shows the results of aggregate stability over time for soil sprayed with pure water (Blank), PVA, and 1:1 mixed of starch and PVA as a dust suppressant. Compared to the starch, the performance of the PVA was relatively superior. The aggregate stability was compared to the blank, excluding the starch, PVA, and the 1:1 mixed dust control agent of starch and PVA. PVA performance was relatively better than starch. The results show that the aggregate stability of the soil to which the dust suppressant was applied had higher aggregate stability compared to the soil to which only water (blank) was applied. These results were attributed to the formation of a larger mass by agglomeration of multiple dispersed soil particles due to a film formation and adhesion reaction between PVA soil particles.

The soils aggregate stability of the PVA treatment zone and the 1:1 blended dust suppressant of the starch and PVA treatment zone was gradually reduced over time. After approximately seven weeks, it was found that the soil stability value remained close to that of the initial aggregate stability value of the blank. This is presumed to be the result of disassembling and showing the film structure with soil particles due to the degradation of the PVA polymer over time. Therefore, it is thought that it is necessary to determine an appropriate application cycle in order to maintain the continuous emission prevention effect of the PVA.

Figure 4. Change of aggregate stability with time for treated and non-treated soils (Blank) with a dust suppressant

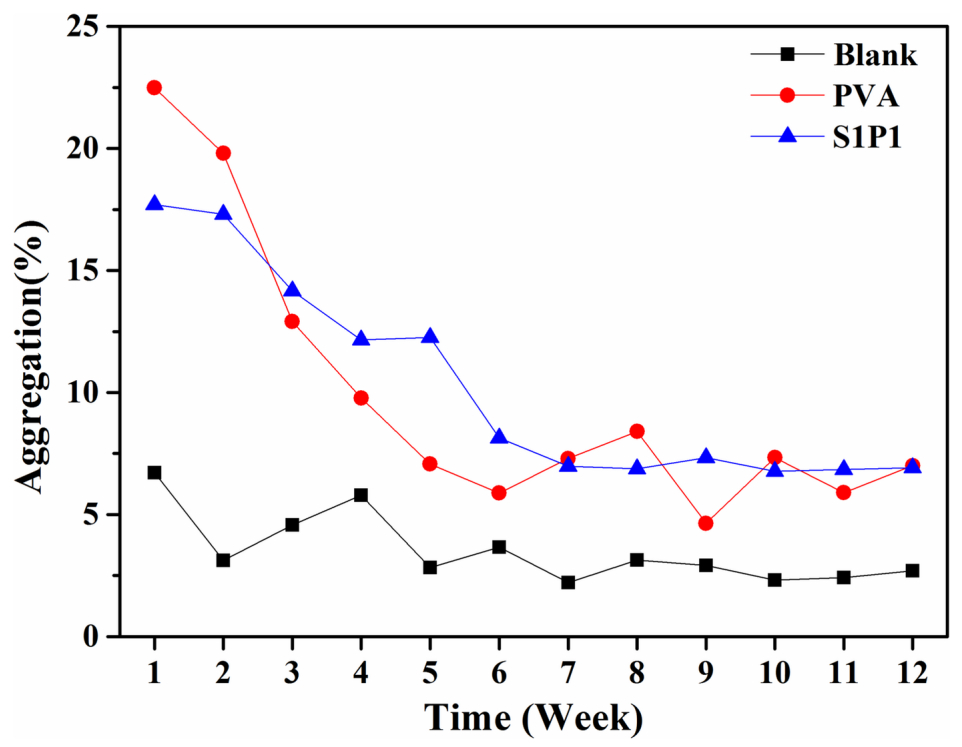




\section{CONCLUSION}

In this study, the researchers investigated the effect of spraying a solution of starch, PVA, and/or 1:1 ratio blended starch and PVA dust suppressant to prevent the emission of soil dust at large construction sites in Seoul. Among them, it was clarified that the dust emitting suppression using PVA was high, and it showed high performance when blended with starch at a ratio of 1:1. Looking at the effect of suppressing the emitting of soil dust by starch and PVA, depending on the applied dust suppressant solution concentration, it was confirmed that $0.05 \mathrm{~g} / \mathrm{L}$ was the appropriate concentration in both cases. It was confirmed that the concentration of $\mathrm{PM}_{10}$ reduced corresponded to the fine dust in the range of "good $\left(0-30 \mu \mathrm{g} / \mathrm{m}^{3}\right.$, day)." With both the starch and PVA at $0.05 \mathrm{~g} / \mathrm{L}$, which is the appropriate concentration condition selected in this study.

In the experiment on the soil suppression effect due to the change of soil texture in the field soil, the quality of loamy sand was higher than the sandy loam, and the soil dust emitting suppression effect was higher than the blank. This is good for sandy loam soil fine particles, which are relatively small fine soil, and a few sand components. Loamy sand, which has less fine dust and many sand components that can easily lead to loose cohesion. When fine dust emitting occurred and a dust suppressant was added, it could be interpreted that these cohesive forces were increased and the occurrence of fine dust emissions were greatly reduced.

This study shows that the aggregate stability of the soil applied with the dust suppressant was greatly increased compared to the blank, which was directly related to the dust-emitting suppression effect. Aggregate stability showed a tendency to decrease over time due to the degradation of bonds formed by the starch and PVA. This study can be used to optimize the usage of starch and PVA, and to assist other researchers in discovering an appropriate application cycle to obtain the desired dust suppression effect. 


\section{REFERENCES}

Adhikari, M., Kim, S., Yadav, D. R., Um, Y. H., Kim, H. S., Lee, H. B., \& Lee, Y. S. et al. (2016). A New record of pseudeurotium bakeri from crop field soil in Korea. Korean J. Mycol., 44(3), 145-149.

Choi, Y. L., Choi, J. S., Yang, J. K., Park, S. H., Joo, H. S., \& Chang, Y. Y. (2018). Application of chemical dust suppressants for control of fugitive dust in ash pond of thermal power plant. Journal of Soil and Groundwater Environment, 23(6), 82-89.

Cohen, A. J., Ross Anderson, H., Ostro, B., Pandey, K. D., Krzyzanowski, M., Künzli, N., \& Smith, K. et al. (2005). The global burden of disease due to outdoor air pollution. Journal of Toxicology and Environmental Health. Part A., 68(13-14), 1301-1307. doi:10.1080/15287390590936166 PMID:16024504

Lu, X., Wang, Y., Li, Y., \& Huang, Q. (2018). Assembly of Pickering emulsions using milled starch particles with different amylose/amylopectin ratios. Food Hydrocolloids, 84, 47-57. doi:10.1016/j.foodhyd.2018.05.045

Park, H. J. (2018). Distribution characteristics and source indentification of ambient PM10 and PM2.5 in Ulsan [Masters dissertation]. Ulsan National Institute of Science and Technology.

Petkova, E. P., Jack, D. W., Volavka-Close, N. H., \& Kinney, P. L. (2013). Particulate matter pollution in African cities. Air Quality, Atmosphere \& Health, 6(3), 603-614. doi:10.1007/s11869-013-0199-6

Priya, B., Gupta, V. K., Pathania, D., \& Singha, A. S. (2014). Synthesis, characterization and antibacterial activity of biodegradable starch/PVA composite films reinforced with cellulosic fibre. Carbohydrate Polymers, 109, 171-179. doi:10.1016/j.carbpol.2014.03.044 PMID:24815414

Reinhart, K. O., \& Vermeire, L. T. (2016). Soil aggregate stability and grassland productivity associations in a northern mixed-grass prairie. PLoS One, 11(7), e0160262. doi:10.1371/journal.pone.0160262 PMID:27467598

Sadhu, S. D., Soni, A., Varmani, S. G., \& Garg, M. (2014). Preparation of starch-poly vinyl alcohol (PVA) blend using potato and study of its mechanical properties. Int. J. Pharm. Sci. Invent, 3(3), 33-37.

Seo, Y. H. (2011). A laboratory study on short-term efficiencies of chemical dust suppressants to reduce fugitive dust [Masters dissertation]. Incheon National University.

Stokes, G. G. (1901). On the effect of the internal friction of fluids on the motion of pendulums. Trans. Cambridge Philos. Soc., 9, 1-141.

Wang, S., Li, C., Copeland, L., Niu, Q., \& Wang, S. (2015). Starch retrogradation: A comprehensive review. Comprehensive Reviews in Food Science and Food Safety, 14(5), 568-585. doi:10.1111/1541-4337.12143 
Jong-Soo Choi is doing a Ph.D. at the Department of Environmental Engineering, Kwangwoon University, Seoul 01897, Korea. He has been published around 8 research papers in peer-reviewed journals and two are under communication. Also, he has presented results at various International and National Conferences. His research interest is"Synthesis and characterization of composite material based on Graphene and others for adsorption of organic and inorganic pollutants from water."

Dong-Su Kim is doing a Ph.D. at the Department of Environmental Engineering, Kwangwoon University, Seoul 01897, Korea. His research interest is"Synthesis and characterization of composite material based on Graphene and others for adsorption as biochar of organic and inorganic pollutants from water."

Yu-Lim Choi is doing a Ph.D. at the Department of Environmental Engineering, Kwangwoon University, Seoul 01897, Korea. Also, he has been presented my research results at various International and National Conferences. His research interest is "Synthesis and characterization of composite material based on Graphene and others for adsorption of organic and inorganic pollutants from water."

L. Lakshmi Prasanna $(P h D)$ is working as a Post-Doctoral Fellow in the Department of Environmental Engineering, Kwangwoon University, Seoul 01897, Korea. She has been published around 30 research papers in peer-reviewed journals and two are under communication. Also, I have been presented my research results at various International and National Conferences. Her research interest is"Synthesis and characterization of Nanocomposite material based on Graphene and others. Ground Water and wastewater treatment. Synthesis of various Organic compounds and their applications. Adsorption of organic and inorganic pollutants from water. Photo degradations of organic pollutants by using nanomaterials."

Janardhan Reddy Koduru (PhD) currently is associate professor of Environmental Engineering at Kwangwoon University, Seoul, Korea. He received Ph.D. in Chemistry in 2007 from S. V. University, Tirupati, A.P., India. After his post-doctoral fellowship (2008-2010) at Kyungpook National University, Korea, he worked as assistant professor of Chemistry and Environmental Engineering at Dongguk University, Kwangwoon University South Korea (2011-2016), respectively. His research interests include the development of low-toxicity nanocomposites for sustainable energy and environmental remediation. He received many prestigious awards from various academic agencies; include CSIR-SRF, Aufau International Young Scientist in Chemical and Environmental Sciences, the Environmentalist of the Year 2016 from NESA and Publons peer review awards. His biography recognized by Marquis Who's Who in the World and published in 33rd Edition. He has published around 90 papers and submitted three Korean patents. He has received many academic presentation awards from various conference organizations and associated with many societies and journals as a life member, an editorial board member, and an editorial advisor.

Jae-Kyu Yang $(P h D)$ is currently working as a professor of Environmental Engineering at Kwangwoon University, Seoul, Korea. Prof. Yang research interests include the development of low-toxicity nanocomposites for sustainable energy and environmental remediation. He has received many academic presentation awards from various conference organizations and associated with many societies and journals as a life member, an editorial board member, and an editorial advisor. He published more than 120 papers in peer-reviewed journals.

Yoon-Young Chang $(P h D)$ is currently working as a professor of Environmental Engineering at Kwangwoon University, Seoul, Korea. Prof. Chang research interests include the development of low-toxicity nanocomposites for sustainable energy and environmental remediation. He has received many academic presentation awards from various conference organizations and associated with many societies and journals as a life member, an editorial board member, and an editorial advisor. He published more than 130 papers in peer-reviewed journals. 